\title{
Is overall asthma control being achieved? A hypothesis-generating study
}

\author{
E.D. Bateman*, J. Bousquet", G.L. Braunstein
}

\begin{abstract}
Is overall asthma control being achieved? A hypothesis-generating study. E.D. Bateman, J. Bousquet, G.L. Braunstein. (C) ERS Journals Ltd 2001.

ABSTRACT: The efficacy of asthma therapy is traditionally measured using single end-points. In contrast, the aim of therapy is to achieve overall control, defined by management guidelines as achieving a number of treatment goals. These goals reflect expert opinion, rather than being evidence based. The objective of this study was to determine whether guideline-defined asthma control is achievable.

Eight studies of salmeterol/fluticasone propionate combination therapy were analysed using three asthma control measures of varying stringency, derived from the guideline goals. For each measure, only patients meeting all goals were classified as controlled.

The analysis demonstrated that asthma control, as defined by management guidelines, can be achieved. For a given therapy, similar proportions of patients achieved control irrespective of disease severity, suggesting that outcome expectations should not be reduced for patients with more severe disease. Substantially more patients achieved the target values for individual goals than achieved overall control, indicating that reliance on individual end-points is likely to result in significant overestimation of true control.

The findings of this hypothesis-generating study should be prospectively tested. Future research will include a randomized controlled study designed to assess the proportion of patients able to achieve overall control of asthma when treatment is titrated appropriately.
\end{abstract}

Eur Respir J 2001; 17: 589-595.

\begin{abstract}
*UCT Lung Institute, University of Cape Town, Cape Town, South Africa, ${ }^{\#}$ Hôpital Arnaud de Villeneuvre, Montpellier, France and "GlaxoSmithkline Research and Development, Stockley Park, Uxbridge, UK.
\end{abstract}

Correspondence: E.D. Bateman, UCT Lung Institute, Groote Schuur 7937, Cape Town, South Africa, PO Box 34560

Fax: 27214066902

Keywords: Asthma control, budesonide, drug therapy, fluticasone propionate, guidelines, salmeterol

Received: October 42000

Accepted after revision November 30 2000

This study was sponsored by GlaxoSmithkline. Seretide ${ }^{\mathrm{TM}}$, Advair ${ }^{\mathrm{TM}}$, Viani $^{\mathrm{TM}}$ and Diskus ${ }^{\mathrm{TM}}$ are trademarks of the GlaxoSmithkline group.
In clinical studies researchers have traditionally measured the efficacy of a treatment in terms of the change from baseline in a single primary end-point, notably lung function. In contrast, the aim of asthma management is to achieve control of the disease. Asthma management guidelines define control in terms of meeting each of a series of "treatment goals", including symptoms, rescue $\beta_{2}$-agonist use, exacerbations, lung function and adverse effects of medication [1-3]. However, these goals are based on expert opinion, rather than being evidence based. Although other studies have investigated various aspects of asthma control, including the time course of improvement, and associations between control and quality of life [4-8], whether guideline-defined control can in fact be achieved has not previously been determined.

The benefits of combination therapy with a longacting $\beta_{2}$-agonist and inhaled corticosteroid, compared with inhaled corticosteroid therapy alone, are now well recognized. Trials included in the recent clinical development programme for a combination product containing both salmeterol xinafoate and fluticasone propionate $(\mathrm{FP})$ in a single Diskus ${ }^{\mathrm{TM}}$ dry powder inhaler (salmeterol/fluticasone propionate combination (SFC), Seretide ${ }^{\mathrm{TM}} /$ Advair $^{\mathrm{TM}} / \mathrm{Viani}^{\mathrm{TM}}$ ) [9-16] provided an opportunity to examine the level of asthma control achieved in patients with a range of asthma severity during treatment with inhaled corticosteroids and salmeterol given either alone or in combination. To the authors' knowledge, this hypothesis-generating study is the first attempt to determine whether guidelinedefined asthma control is achievable.

\section{Methods}

\section{Studies and population}

Trials selected for inclusion in the analysis were all SFC Diskus ${ }^{\mathrm{TM}}$ studies that had a finalized database at the end of 1998 [9-16] (table 1). With the exception of prior treatment, the inclusion criteria in each of these comparative randomized, double-blind, parallelgroup studies were similar, with only patients who were poorly controlled on existing therapy randomized to treatment. Nearly 2,800 patients, with a range of asthma severity, were included in the analysis. All drugs were administered twice daily via a dry powder inhaler.

Five studies compared the SFC Diskus ${ }^{\mathrm{TM}}$ with inhaled corticosteroid therapy alone in adolescents and adults (A1, A2, B3, C1 and C2). In three studies (A1, 
Table 1. - Studies included in the analysis

\begin{tabular}{|c|c|c|c|c|c|c|}
\hline \multirow[b]{2}{*}{ Study } & \multirow[b]{2}{*}{ [Ref.] } & \multirow[b]{2}{*}{$\begin{array}{l}\text { Duration } \\
\text { (age) }\end{array}$} & \multirow[b]{2}{*}{$\begin{array}{l}\text { Symptoms/rescue } \\
\text { medication }\end{array}$} & \multicolumn{2}{|c|}{ Inclusion criteria } & \multirow[b]{2}{*}{ Comparator treatment (n) } \\
\hline & & & & FEV1/PEF & $\begin{array}{l}\text { Previous treatment } \\
(\text { dose } \mu \mathrm{g})\end{array}$ & \\
\hline A1 & [9] & $\begin{array}{l}12 \text { weeks } \\
(\geqslant 12 \text { yrs })\end{array}$ & $\begin{array}{l}\text { During } 2 \text {-week run-in; } \\
\leqslant 3 \text { nights needing } \\
\text { rescue medication, } \leqslant 3 \\
\text { days with } \geqslant 12 * \text { puffs } \\
\text { rescue medication }\end{array}$ & $\begin{array}{l}\text { FEV } 1 \\
40-85 \% \text { pred }\end{array}$ & $\begin{array}{l}\text { SALM }(100) \\
\text { BDP }(300-500) \\
\text { TCA }(600-1000) \\
\text { FLU }(1000) \text { FP }(200)\end{array}$ & $\begin{array}{l}\text { SFC } 50 / 100 \mu \mathrm{g} \text { b.i.d. (92) } \\
\text { SALM } 50 \mu \mathrm{g} \text { b.i.d. (92) } \\
\text { FP } 100 \mu \mathrm{g} \text { b.i.d. (90) PL (82) }\end{array}$ \\
\hline A2 & {$[10]$} & $\begin{array}{l}12 \text { weeks } \\
(\geqslant 12 \text { yrs })\end{array}$ & As for A1 & $\begin{array}{l}\text { FEV } 1 \\
40-85 \% \text { pred }\end{array}$ & $\begin{array}{l}\text { BDP }(550-800) \\
\text { TCA }(1100-1600) \\
\text { FLU }(1250-2000) \\
\text { FP }(500)\end{array}$ & $\begin{array}{l}\text { SFC } 50 / 250 \mu \mathrm{g} \text { b.i.d. (84) } \\
\text { SALM } 50 \mu \mathrm{g} \text { b.i.d. (88) } \\
\text { FP } 250 \mu \mathrm{g} \text { b.i.d. }(84) \\
\text { PL (93) }\end{array}$ \\
\hline $\mathrm{B} 1$ & {$[11]$} & $\begin{array}{l}12 \text { weeks } \\
(\geqslant 12 \text { yrs })\end{array}$ & $\begin{array}{l}\text { During week before } \\
\text { randomization: } \geqslant 3 \\
\text { days with day }+ \text { night } \\
\text { symptom score } \geqslant 2\end{array}$ & $\begin{array}{l}\text { PEF } 50-85 \% \text { of } \\
\text { postsalbutamol } \\
\text { value }\end{array}$ & $\begin{array}{l}\text { BDP/BUD (400-500) } \\
\text { FP (200-250) }\end{array}$ & $\begin{array}{l}\text { SFC } 50 / 100 \mu \mathrm{g} \text { b.i.d. }(21) \\
\text { SALM } 50 \mu \mathrm{g} \text { b.i.d. }+ \text { FP } 100 \mu \mathrm{g} \\
\text { b.i.d. (concurrently) }+(123)\end{array}$ \\
\hline B2 & {$[12]$} & $\begin{array}{l}12 \text { weeks } \\
(\geqslant 12 \text { yrs })\end{array}$ & As for B1 & $\begin{array}{l}\text { PEF } 50-85 \% \text { of } \\
\text { postsalbutamol } \\
\text { value }\end{array}$ & $\begin{array}{l}\text { BDP/BUD (800-1200) } \\
\text { FP (400-600) }\end{array}$ & $\begin{array}{l}\text { SFC } 50 / 250 \mu \mathrm{g} \text { b.i.d. }(180) \\
\text { SALM } 50 \mu \mathrm{g} \text { b.i.d. + FP } 250 \mu \mathrm{g} \\
\text { b.i.d. (concurrently) + (191) }\end{array}$ \\
\hline B3 & {$[13]$} & $\begin{array}{l}28 \text { weeks } \\
(\geqslant 12 \text { yrs })\end{array}$ & As for $\mathrm{B} 1$ & $\begin{array}{l}\text { PEF } 50-85 \% \text { of } \\
\text { postsalbutamol } \\
\text { value }\end{array}$ & $\begin{array}{l}\text { BDP/BUD (1500-2000) } \\
\text { FP (750-1000) }\end{array}$ & $\begin{array}{l}\text { SFC } 50 / 500 \mu \mathrm{g} \text { b.i.d. }(167) \\
\text { SALM } 50 \mu \mathrm{g} \text { b.i.d. }+ \text { FP } 500 \mu \mathrm{g} \\
\text { b.i.d. (concurrently) }+(171) \\
\text { FP } 500 \mu \mathrm{g} \text { b.i.d. }(165)\end{array}$ \\
\hline B4 & {$[14]$} & $\begin{array}{l}12 \text { weeks } \\
(4-11 \text { yrs })\end{array}$ & $\begin{array}{l}\text { During week before } \\
\text { randomization: } \geqslant 4 \\
\text { days with day }+ \text { night } \\
\text { symptom score } \geqslant 1\end{array}$ & $\begin{array}{l}\text { PEF } 50-85 \% \text { of } \\
\text { postsalbutamol } \\
\text { value }\end{array}$ & $\begin{array}{l}\text { BDP/BUD (400-500) } \\
\text { FP (200-250) }\end{array}$ & $\begin{array}{l}\text { SFC } 50 / 100 \mu \mathrm{g} \text { b.i.d. }(125) \\
\text { SALM } 50 \mu \mathrm{g} \text { b.i.d. }+ \text { FP } 100 \mu \mathrm{g} \\
\text { b.i.d. (concurrently) }+(132)\end{array}$ \\
\hline $\mathrm{C} 1$ & {$[15]$} & $\begin{array}{l}12 \text { weeks } \\
(\geqslant 12 \mathrm{yrs})\end{array}$ & $\begin{array}{l}\text { During week before } \\
\text { randomization: } \geqslant 4 \\
\text { days with day }+ \text { night } \\
\text { symptom score } \geqslant 2\end{array}$ & $\begin{array}{l}\text { FEV } 1 \\
65-85 \% \text { pred }\end{array}$ & $\mathrm{BDP} / \mathrm{BUD}(\leqslant 500)$ & SFC 50/100 $\mu \mathrm{g}$ b.i.d. (176) \\
\hline $\mathrm{C} 2$ & {$[16]$} & $\begin{array}{l}24 \text { weeks } \\
(\geqslant 12 \text { yrs })\end{array}$ & As for $\mathrm{Cl}$ & $\begin{array}{l}\text { FEV } 1 \\
50-85 \% \text { pred }\end{array}$ & BDP/BUD (800-1200) & $\begin{array}{l}\text { SFC } 50 / 250 \mu \mathrm{g} \text { b.i.d. (180) } \\
\text { BUD } 800 \mu \mathrm{g} \text { b.i.d. (173) }\end{array}$ \\
\hline
\end{tabular}

FEV1: forced expiratory volume in one second; PEF: peak expiratory flow; b.i.d: twice daily; BDP: beclomethasone dipropionate; BUD: budesonide; FLU: flunisolide; FP: fluticasone propionate; PL: placebo; SALM: salmeterol; SFC: salmeterol/fluticasone propionate combination; TCA: triamcinolone acetonide; *: for patients previously on inhaled corticosteroids ( $\geqslant 6$ puffs for those on SALM).

A2 and B3) the comparator corticosteroid was FP administered at the same dose as in the SFC arm of the studies. In the other two studies (C1 and C2) SFC was compared with a three- $(\mathrm{C} 1)$ to four-fold $(\mathrm{C} 2)$ higher dose of budesonide. Studies A1 and A2 also included a group treated with salmeterol alone and a placebo group treated with rescue short-acting $\beta_{2}$-agonists only. Analysis of these five studies enabled comparison of the relative effectiveness, in terms of asthma control, of SFC versus inhaled corticosteroids at equivalent or higher doses, salmeterol therapy alone, and placebo.

Three studies (B1, B2 and B3) compared SFC with equivalent doses of salmeterol and FP administered via two separate Diskus ${ }^{\mathrm{TM}}$ inhalers (concurrent treatment) in adolescents and adults. Analysis of these three studies provided information on the levels of overall control achievable in patients with asthma of varying severity, treated with three different SFC doses. A paediatric study (B4) with the same design provided information on asthma control in children aged 4-11 yrs treated with SFC or concurrent salmeterol and FP therapy.

\section{Measures of asthma control}

Data were available from patient diary cards (daytime and night-time symptom scores, use of rescue short-acting $\beta_{2}$-agonists, morning and evening peak expiratory flow (PEF) (amPEF and pmPEF, respectively)) and from case record forms (exacerbations, adverse drug reactions). Data were collected in a broadly similar manner across all studies. Details of the daytime and night-time symptom scoring systems used in the eight studies are given in table 2.

In order to test the robustness of the findings, the database was reviewed using three different measures of asthma control (table 3 ) derived from the treatment goals comprising the definition of asthma control stipulated in the Global Initiative for Asthma (GINA) guidelines. As some of these goals are expressed only as qualitative targets ("minimal," "ideally no") it was necessary to assign quantitative values to enable analysis of the clinical trial data, using pragmatic clinical interpretation. For the primary measure (level 2) the goals were interpreted as follows: "minimal 
Table 2. - Symptom scoring systems

\begin{tabular}{ll}
\hline Score & Definition \\
\hline $\begin{array}{l}\text { Studies A1-2 } \\
\text { Asthma symptom score* }\end{array}$ & \\
0 & No symptoms during the day \\
1 & Symptoms for one short period during the day \\
2 & Symptoms for 2 or more short periods during the day \\
3 & Symptoms for most of the day which did not affect my normal daily activities \\
4 & Symptoms for most of the day which did affect my normal daily activities \\
5 & Symptoms so severe that I could not go to work/school or perform normal daily activities \\
Number of night-time & \\
awakenings due to asthma & \\
0 & No night-time awakenings \\
1 & Symptoms causing me to wake once or wake early \\
2 & Symptoms causing me to wake twice (including waking early) \\
3 & Symptoms causing me to wake three times (including waking early) \\
Studies B1-4, C1-2 & \\
Daytime symptom score ${ }^{+}$ & No symptoms during the day \\
0 & Symptoms for one short period during the day \\
1 & Symptoms for 2 or more short periods during the day \\
2 & Symptoms for most of the day which did not affect my normal daily activities \\
3 & Symptoms for most of the day which did affect my normal daily activities \\
4 & Symptoms so severe that I could not go to work/school or perform normal daily activities \\
5 & No symptoms during the night \\
Night-time symptom score & \\
0 & Symptoms causing me to wake once or wake early \\
1 & Symptoms causing me to wake twice or more (including waking early) \\
3 & Symptoms causing me to be awake for most of the night \\
4 & Symptoms so severe that I did not sleep at all \\
\hline
\end{tabular}

*: recorded in morning and relates to previous $24 \mathrm{~h} ;{ }^{*}$ : recorded in morning and relates to previous night; ": the score was infinite and represented the number of times a patient awoke requiring salbutamol i.e. a patient could record any number; ${ }^{+}$: recorded in evening and relates to current day.

(ideally no) symptoms" was defined as a daytime asthma score of 0 (no symptoms) or 1 (symptoms for one short period), and a night-time asthma score of 0 (no symptoms/awakening); "minimal (ideally no)" use of rescue medication was interpreted as no more than one inhalation of salbutamol per day. The goals relating to exacerbations, adverse drug reactions, amPEF and PEF diurnal variation (calculated as $(\mathrm{pmPEF}-\mathrm{amPEF}) /((\mathrm{amPEF}+\mathrm{pmPEF}) / 2)$ were expressed in quantitative terms in the GINA guidelines, and were therefore included in the level 2 control measure in their original form. Although also an important goal of treatment, activity limitation was not measured in the studies analysed, and was therefore excluded from the control measured used for the analysis.

A stricter measure of asthma control was also considered (level 1). For this measure the daytime symptom score and use of rescue $\beta_{2}$-agonist were zero, amPEF was $>85 \%$ pred, and night-time symptom score was zero. A third measure was also used (level 3), based on a more pragmatic approach, describing a level of control which, if not achieved, would necessitate an immediate change in therapy. This was the least stringent of the asthma control measures used for the analyses.

Table 3. - Guideline-derived measures of control

\begin{tabular}{|c|c|c|c|}
\hline GINA treatment goals & Level 1 control & Level 2 control & Level 3 control \\
\hline $\begin{array}{l}\text { Minimal (ideally no) chronic } \\
\text { symptoms, including } \\
\text { nocturnal symptoms } \\
\text { Minimal (infrequent) episodes } \\
\text { No emergency visits } \\
\text { Minimal need for rescue } \\
\beta_{2} \text {-agonist } \\
\text { No limitations on activities, } \\
\text { including exercise } \\
\text { PEF variability <20\% } \\
\text { (Near) normal PEF } \\
\text { Minimal (or no) adverse } \\
\text { effects from medicine }\end{array}$ & $\begin{array}{l}\text { Symptom score } 0 \\
\text { (daytime and night- } \\
\text { time) } \\
\text { No exacerbations } \\
\text { No use of rescue } \\
\text { medication } \\
\text { Diurnal variation in } \\
\text { PEF }<20 \% \\
\text { amPEF }>85 \% \text { pred } \\
\text { No treatment related } \\
\text { adverse events }\end{array}$ & $\begin{array}{l}\text { Symptom score - } \\
\text { day: } 0 \text { or } 1 \text {; night: } 0 \\
\text { No exacerbations } \\
\text { Rescue medication } \\
\leqslant \text { once daily } \\
\text { Diurnal variation in } \\
\mathrm{PEF}<20 \% \\
\text { amPEF } \geqslant 80 \% \text { predicted } \\
\text { No treatment-related } \\
\text { adverse events }\end{array}$ & $\begin{array}{l}<4 \text { consecutive days with symptoms } \\
\text { (night-time score }>0 \text {, daytime score } \\
>1 \text { ) or amPEF }<80 \% \text { predicted, or } \\
\text { diurnal variations in PEF }>20 \% \\
\text { No more than three nocturnal } \\
\text { awakenings in any month } \\
\text { No more that } 3 \text { days with } \\
\text { symptoms (night-time score }>0 \text {, } \\
\text { daytime score }>1 \text { ) in any week } \\
\text { No moderate or severe exacerbations } \\
\text { No more than one can of rescue } \\
\text { medication ( } 200 \text { puffs) in any month } \\
\text { No treatment-related adverse events }\end{array}$ \\
\hline
\end{tabular}

GINA: Global Initiative for Asthma; PEF: peak expiratory flow. 


\section{Statistical analysis}

This was a hypothesis-generating study rather than a formal meta-analysis of particular interventions or drugs. The analysis was based on an 8-week assessment period (treatment weeks 5-12). Data from the first 4 weeks of treatment were excluded to ensure that the analysis was performed on the plateau of the effect for all treatments, and to avoid bias towards groups who were receiving bronchodilator therapy, as this would be expected to take effect more rapidly than inhaled corticosteroid therapy. The majority of studies were of 12 weeks duration and any data collected beyond week 12 were also excluded.

Two approaches were taken for the analysis. Firstly, for control levels 1 and 2, the number of patients with controlled asthma for each day of the assessment was determined. Each criterion (table 3) was assessed independently on a daily basis. A subject was considered to have a controlled day unless there was evidence that one or more of the individual criteria had not been met. If more than four criteria were missing on a particular day for a subject, the subject concerned was excluded from the analysis for that particular day. Subjects who were withdrawn for lack of efficacy or an exacerbation of asthma were classed as uncontrolled for the remainder of the assessment period. Where withdrawal was for another reason, their subsequent data were regarded as missing.

A different approach was used for level 3 asthma control, in which control for each criterion was determined relative to the appropriate time period (table 3 ) for that criterion. For example, a subject was considered controlled for night-time awakening until the fourth occurrence in a month, after which they were considered uncontrolled for the remainder of that month i.e. as permitted by the level 3 measure, a patient could have three night-time awakenings in any given month before their asthma was considered to be uncontrolled for the remaining days of that month (table 3). Withdrawals and exacerbations were handled as described above.

For all levels of control the percentage of subjects achieving control for $95 \%$ of weeks 5-12 i.e. for at least 54 of the 56 days, was calculated, and these patients were classed as having achieved overall control. Additionally, for levels 1 and 2 only, the mean number of days controlled by treatment group were calculated. This was not calculated for level 3 as the criteria comprising this measure were themselves timedependent.

In addition to analysis of overall asthma control as described above, the proportions of patients achieving control in terms of each individual guideline treatment goal, namely daytime and night-time asthma symptoms, use of rescue medication, PEF, diurnal variation in PEF, exacerbations and adverse events, were also determined.

\section{Results}

The analysis shows that control of asthma was achievable in a proportion of patients and for a proportion of days in all studies (tables 4 and 5). Expressing the results in terms of the percentage of days controlled gave consistently higher proportions controlled than expressing the results in terms of the

Table 4. - Mean proportion of patients controlled for $95 \%$ of study period

\begin{tabular}{|c|c|c|c|c|c|}
\hline \multirow{2}{*}{ Study } & \multirow{2}{*}{ [Ref.] } & \multirow{2}{*}{ Treatment } & \multicolumn{3}{|c|}{$\begin{array}{l}\text { Percentage of patients controlled for } 95 \% \text { of days during weeks } 5-12(95 \% \mathrm{CI}) \\
\text { Measure of control }\end{array}$} \\
\hline & & & Level 1 & Level 2 & Level 3 \\
\hline \multirow[t]{4}{*}{ A1 } & {$[9]^{*}$} & SFC & $13(6-20)$ & $27(18-36)$ & $45(35-55)$ \\
\hline & & SALM & $3(-1-7)$ & $5(1-10)$ & $17(9-25)$ \\
\hline & & FP & $2(-1-5)$ & $10(4-16)$ & $26(17-35)$ \\
\hline & & $\mathrm{PL}^{*}$ & $1(-1-3)$ & $3(-1-7)$ & $15(7-23)$ \\
\hline \multirow[t]{4}{*}{ A2 } & {$[10]^{\#}$} & SFC & $9(3-15)$ & $27(17-37)$ & $49(38-60)$ \\
\hline & & SALM & $0(0-0)$ & $4(0-8)$ & $24(15-33)$ \\
\hline & & FP & $4(0-8)$ & $16(8-24)$ & $39(28-50)$ \\
\hline & & PL & $1(-1-3)$ & $3(-1-7)$ & $28(19-37)$ \\
\hline \multirow[t]{2}{*}{ B1 } & [11] & SFC & $7(2-12)$ & $13(7-19)$ & $30(22-38)$ \\
\hline & & SALM + FP concurrently & $10(5-15)$ & $18(11-25)$ & $31(23-39)$ \\
\hline \multirow{2}{*}{ B2 } & [12] & SFC & $5(2-8)$ & $10(6-15)$ & $22(16-28)$ \\
\hline & & SALM + FP concurrently & $3(1-6)$ & $7(3-11)$ & $21(15-27)$ \\
\hline \multirow[t]{3}{*}{ B3 } & [13] & $\mathrm{SFC}$ & $8(4-12)$ & $13(8-18)$ & $24(17-31)$ \\
\hline & & SALM + FP concurrently & $7(3-11)$ & $11(6-16)$ & $21(15-27)$ \\
\hline & & FP & $4(1-7)$ & $4(1-7)$ & $18(12-24)$ \\
\hline \multirow{2}{*}{ B4 } & [14] & SFC & $7(2-12)$ & $15(9-21)$ & $29(21-37)$ \\
\hline & & SALM + FP concurrently & $5(1-9)$ & $10(5-15)$ & $29(21-37)$ \\
\hline \multirow{2}{*}{$\mathrm{C} 1$} & [15] & SFC & $20(14-26)$ & $27(20-34)$ & $36(29-43)$ \\
\hline & & BUD & $15(10-20)$ & $20(14-26)$ & $34(27-41)$ \\
\hline \multirow{2}{*}{$\mathrm{C} 2$} & [16] & $\mathrm{SFC}$ & $11(6-16)$ & $17(11-23)$ & $23(17-29)$ \\
\hline & & BUD & $5(2-8)$ & $7(3-11)$ & $12(7-17)$ \\
\hline
\end{tabular}

95\% CI: 95\% confidence interval; *: approximately 70\% of patients were previously taking inhaled corticosteroids; ${ }^{*}:$ all patients were previously taking inhaled corticosteroids; BUD: budesonide; FP: fluticasone propionate; PL: placebo; SALM: salmeterol; SFC: salmeterol/fluticasone propionate combination product. 
Table 5. - Mean proportion of days controlled

\begin{tabular}{|c|c|c|c|c|}
\hline \multirow[b]{2}{*}{ Study } & \multirow[b]{2}{*}{ [Ref.] } & \multirow[b]{2}{*}{ Treatment } & \multicolumn{2}{|c|}{$\begin{array}{c}\text { Mean percentage of days } \\
\text { controlled during weeks } 5-12 \\
(95 \% \mathrm{CI}) \\
\text { Measure of control } \\
\end{array}$} \\
\hline & & & Level 1 & Level 2 \\
\hline \multirow[t]{4}{*}{ A1 } & {$[9]^{*}$} & $\mathrm{SFC}$ & $34(26-42)$ & $51(42-60)$ \\
\hline & & SALM & $10(5-15)$ & $19(13-26)$ \\
\hline & & FP & $13(8-19)$ & $30(22-38)$ \\
\hline & & PL & $8(3-13)$ & $13(7-19)$ \\
\hline \multirow[t]{4}{*}{ A2 } & {$[10]^{\#}$} & $\mathrm{SFC}$ & $36(28-45)$ & $56(47-65)$ \\
\hline & & SALM & $10(5-15)$ & $16(10-22)$ \\
\hline & & FP & $20(13-27)$ & $33(24-42)$ \\
\hline & & PL & $7(4-10)$ & $16(10-22)$ \\
\hline \multirow[t]{2}{*}{ B1 } & [11] & $\mathrm{SFC}$ & $37(31-44)$ & $46(39-53)$ \\
\hline & & $\begin{array}{l}\text { SALM + FP } \\
\text { concurrently }\end{array}$ & $41(34-48)$ & $50(43-57)$ \\
\hline \multirow[t]{2}{*}{ B2 } & [12] & SFC & $26(21-31)$ & $36(30-42)$ \\
\hline & & $\begin{array}{l}\text { SALM + FP } \\
\text { concurrently }\end{array}$ & $22(18-27)$ & $31(26-36)$ \\
\hline \multirow[t]{3}{*}{ B3 } & [13] & $\mathrm{SFC}$ & $21(16-26)$ & $31(25-37)$ \\
\hline & & $\begin{array}{l}\text { SALM + FP } \\
\text { concurrently }\end{array}$ & $22(17-27)$ & $30(24-36)$ \\
\hline & & FP & $17(12-22)$ & $23(18-28)$ \\
\hline \multirow[t]{2}{*}{$\mathrm{B} 4^{+}$} & [14] & SFC & $44(38-50)$ & $55(49-61)$ \\
\hline & & $\begin{array}{l}\text { SALM + FP } \\
\text { concurrently }\end{array}$ & $43(37-49)$ & $54(48-60)$ \\
\hline \multirow[t]{2}{*}{$\mathrm{C} 1$} & [15] & SFC & $44(38-50)$ & $51(45-57)$ \\
\hline & & BUD & $40(34-46)$ & $50(44-56)$ \\
\hline \multirow[t]{2}{*}{$\mathrm{C} 2$} & [16] & SFC & $31(26-36)$ & $41(35-47)$ \\
\hline & & BUD & $20(15-25)$ & $27(22-33)$ \\
\hline
\end{tabular}

95\% CI: confidence interval; *: approximately $70 \%$ of patients were previously taking inhaled corticosteroids; * all patients were previously taking inhaled corticosteroids; BUD: budesonide; FP: fluticasone propionate; PL: placebo; SALM: salmeterol; SFC: salmeterol/fluticasone propionate combination product; ${ }^{+}$: paediatrics $(4-11 \mathrm{yrs})$.

number of patients controlled (for $95 \%$ of days). For example in study $\mathrm{A} 1$, the mean percentages of days controlled (level 2) were $51 \%, 30 \%, 19 \%$ and $13 \%$ on SFC Diskus ${ }^{\mathrm{TM}}$, FP, salmeterol and placebo, respectively. The corresponding percentages of patients controlled were $27 \%, 10 \%, 5 \%$ and $3 \%$. Predictably the absolute proportions controlled were dependent on the target level of asthma control, with the least stringent measure (level 3) yielding higher percentages than level 2, and the lowest numbers observed for level 1 .
This pattern was observed without exception across studies and treatment arms for both proportions of days controlled (level $2>$ level 1 ) and proportions of patients controlled (level $3>$ level $2>$ level 1). These proportions were also dependent on the nature of treatment, with the same numerical rank order observed across studies for the three levels of control and for both the percentage of days and the percentage of patients controlled: SFC > corticosteroid alone (either FP or budesonide) $>$ salmeterol $>$ placebo.

For all studies and levels of control, the proportions of patients achieving the target value for each individual goal was substantially higher than the proportion of patients achieving control of all goals (overall control). An illustration is given in table 6, using the level 2 measure of control in study A1, which is also representative of the analysis of other studies. Consistently across the studies, three criteria primarily accounted for failure to achieve overall control of symptoms, use of a rescue $\beta_{2}$-agonist, and PEF. In contrast, most patients achieved control of exacerbations, diurnal variation in PEF and adverse events.

Patients with a range of asthma severity were included in this analysis, and accordingly the corticosteroid doses studied were higher in those populations with more severe asthma. The proportions of patients achieving overall asthma control on a given therapy were similar across all studies of similar design (for example $\mathrm{A} 1, \mathrm{~A} 2$, or $\mathrm{B} 1, \mathrm{~B} 2, \mathrm{~B} 3)$, despite the varied asthma severity in the populations studied (table 5).

\section{Discussion}

This study has shown for the first time that asthma control, as defined by asthma management guidelines, can be achieved. The findings were highly reproducible: the rank order of drug efficacy remained the same, irrespective of the stringency of the control measure used or the disease severity of the population studied.

Despite the generally high levels of supervision and compliance during clinical trials, a relatively high proportion of patients failed to achieve overall control of asthma in this study. However, the control measures used were rigorous. For example, a patient who used a rescue $\beta_{2}$-agonist once a day on only three days during

Table 6. - Proportion of patients achieving level 2 asthma control for each individual parameter for $95 \%$ of the treatment period (weeks 5-12) in study A1

\begin{tabular}{lcccc}
\hline Parameter & \multicolumn{4}{l}{ Percentage of patients achieving control for 95\% of days during weeks 5-12 (95\% CI) } \\
\cline { 2 - 4 } & SFC & SALM & FP & PL \\
\hline Symptom score: day 0 or 1; night 0 & $37(27-47)$ & $15(8-22)$ & $29(19-39)$ & $11(4-18)$ \\
No exacerbations & $100(100-100)$ & $95(91-100)$ & $100(100-100)$ & $96(92-100)$ \\
Relief medication $\leqslant$ once daily & $55(45-65)$ & $33(23-43)$ & $34(24-44)$ & $13(6-20)$ \\
PEF diurnal variation $\leqslant 20 \%$ & $81(73-89)$ & $46(36-56)$ & $56(46-67)$ & $29(19-39)$ \\
PEF $\geqslant 80 \%$ predicted & $62(52-72)$ & $21(13-30)$ & $38(28-48)$ & $10(3-17)$ \\
No treatment related adverse events & $87(80-94)$ & $93(88-98)$ & $92(86-98)$ & $98(95-101)$ \\
\hline
\end{tabular}

95\% CI: 95\% confidence interval; PEF: peak expiratory flow; SFC: salmeterol/fluticasone propionate combination product; SALM: salmeterol; FP: fluticasone propionate; PL: placebo. Data from ref [9], where approximately $70 \%$ of patients were previously taking inhaled corticosteroids. 
the 8-week treatment period, but who was controlled on every other parameter, would nevertheless have failed to achieve level 1 control.

Another important factor is that the studies analysed were not originally designed to assess overall asthma control, and the external validity of the findings is therefore limited. Patients with a relatively wide range of asthma severities were able to enter a given study but all patients were then randomized to a single, predefined, constant dose of treatment, considered to be appropriate for the target study population. There was no scope for increasing treatment when required, as recommended in management guidelines. Some patients who failed to achieve asthma control may well have done so if they had been treated with a higher corticosteroid dose. A prospective study with treatment titrated against control is likely to demonstrate that a greater proportion of patients are able to achieve asthma control, as defined by the goals of asthma management guidelines.

The measures of asthma control used for the analysis were derived from management guidelines, and the parameters included are established outcome indicators in the care of individual patients with asthma [17]. The present findings suggest that reliance on the change in individual parameters (as in conventional efficacy analyses) is likely to lead to significant overestimation of true asthma control. Parameters that are commonly used to assess patient well-being in clinical practice, such as PEF or use of rescue medication, may lead clinicians to misclassify poorly controlled patients as adequately controlled if used in isolation. In view of this it may be that assessments should be based on overall consideration of the various parameters which together define asthma control. Such an approach is consistent with current guidelines for asthma management: if control is indeed the goal of therapy, then the focus of therapy should be the extent to which this has been achieved i.e. how close the patient is to the "ceiling", rather than the magnitude of the increase from baseline [18].

Three measures of asthma control were used in the analysis in an attempt to estimate the sensitivity and the robustness of the findings against the criteria used. Interestingly, many of the present findings appear to be independent of the stringency of the control measure used. The fact that the rank order of potency of the therapies (SFC $>$ corticosteroids $>$ salmeterol $>$ placebo) was the same regardless of the level of control achieved, suggests that this order is genuine. This also reflects the results shown with single efficacy parameters. Any one of these three measures could therefore be used for the purposes of drug comparison. However, it is also clear that the absolute proportion of patients achieving control is highly dependent upon the measure used. It is therefore critical to carefully examine the criteria used in any study designed to investigate asthma control, not least because the definitions used in the literature vary widely. For example, two recent studies $[19,20]$ have used "asthma control days" as an endpoint. However, the definition of "asthma control days" differed between these studies and therefore the results cannot be meaningfully compared. In addition, no measures of lung function were included in either definition, despite the importance of this particular parameter in determining overall asthma control (as emphasized by the current analysis). The numbers of "asthma control days" reported in these studies are therefore potentially overestimates of asthma control as described in the GINA guidelines, and unidentified potential for further improvement may persist.

Although management guidelines advocate achievement of asthma control as the goal of therapy, irrespective of initial disease severity, appreciation of this may be limited in everyday clinical practice. CoCKCROFT and SWYSTUN [21] reported that, for patients with more severe disease, many physicians equate therapeutic success with a reduction in symptom severity, rather than aiming for optimal control. However, the apparent lack of a relationship between disease severity at entry to the three sister studies B1, B2 and B3 (as defined by dose of inhaled corticosteroid) and the proportions of patients achieving asthma control, suggests that reducing outcome expectations for patients with more severe disease may be inappropriate. It may be that such patients are as capable of achieving high levels of control as those with milder disease. This will be prospectively studied.

In future work, consideration should be given to exploring alternative measures of asthma control. Identifying a measure of asthma control suitable for use in clinical practice will necessarily be a compromise between what is theoretically optimal and what is pragmatically appropriate. For many patients, failure to achieve control indicates the need for increased therapy. If the control measure applied is unduly stringent, an inappropriately high proportion of patients will be classified as uncontrolled, resulting in some in unnecessary increases in therapy, with concomitant increases in both costs and the risk of adverse effects. Conversely, if the control measure used is too relaxed, a significant proportion of patients may remain under-treated. In the present analysis, three criteria were the primary determinants of overall control, namely symptoms, use of rescue medication and PEF. Development of a simple tool for determination of asthma control, similar to that proposed by JunIPER et al. [5] in the Asthma Control Questionnaire and based primarily on these three criteria may be of value for use in primary care.

In conclusion, the analysis has demonstrated that asthma control, as defined by management guidelines, is achievable, at least in a proportion of patients in these clinical studies. Assessment of control should be based on a number of parameters, as using single endpoints significantly overestimates true asthma control. This was a hypothesis-generating study upon which further prospective studies should be based. A randomized controlled study designed to assess the proportion of patients with persistent asthma who are able to achieve guideline-defined control of asthma when treatment is titrated appropriately is currently underway (GOAL - Gaining Optimal Asthma Control, protocol number SAM40027). It is anticipated that completion of the Asthma Quality of Life Questionnaire [8] at each clinic visit will enable the relationship between guideline-defined asthma control and quality of life to be further defined. In addition, and further to 
the observation that there is no apparent relationship between asthma severity and the proportion of patients achieving overall control, it is anticipated that the Gaining Optimal Asthma Control study will confirm whether achieving overall control of asthma is a realistic treatment aim for all patients with persistent asthma, regardless of asthma severity.

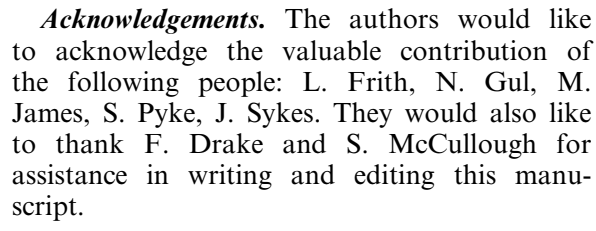
to acknowledge the valuable contribution of the following people: L. Frith, N. Gul, M. James, S. Pyke, J. Sykes. They would also like to thank F. Drake and S. McCullough for assistance in writing and editing this manuscript.

\section{References}

1. Global Initiative for Asthma. Global strategy for asthma management and prevention. NHLBI/WHO workshop report March 1993. Revised November 1998. Bethesda, National Institutes of Health, National Heart, Lung and Blood Institute. Publication number 96-3659B.

2. British Thoracic Society. The British guidelines on asthma management 1995 review and position statement. Thorax 1997; 52: Suppl. 1, S1-S21.

3. National Asthma Education Prevention Program. Guidelines for the diagnosis and management of asthma. Expert panel report 2. Bethesda, National Institutes of Health, National Heart, Lung and Blood Institute 1997. Publication number 97-4051.

4. Vollmer WM, Markson LE, O'Connor E, et al. Association of asthma control with health care utilization and quality of life. Am J Respir Crit Care Med 1999; 160: 1647-1652.

5. Juniper EF, O'Byrne PM, Guyatt GH, Ferrie PJ, King DR. Development and validation of a questionnaire to measure asthma control. Eur Respir J 1999; 14: 902 907.

6. Reddel HK, Jenkins CR, Marks GB, et al. Optimal asthma control, starting with high doses of inhaled budesonide. Eur Respir J 2000; 16: 226-235.

7. Juniper EF, O'Byrne PM, Ferrie PJ, King DR, Roberts JN. Measuring asthma control. Clinic questionnaire or daily diary? Am J Respir Crit Care Med 2000; 162: 1330-1334.

8. Juniper EF, Buist AS, Cox FM, Ferrie PJ, King DR. Validation of a standardized version of the Asthma Quality of Life Questionnaire. Chest 1999; 115: 12651270.

9. Kavuru M, Melamed J, Gross G, et al. Salmeterol and fluticasone propionate combined in a new powder inhalation device for the treatment of asthma: a randomized, double-blind, placebo-controlled trial. J Allergy Clin Immunol 2000; 105: 1108-1116.

10. Shapiro G, Lumry W, Wolfe J, et al. Combined salmeterol $50 \mu \mathrm{g}$ and fluticasone propionate $250 \mu \mathrm{g}$ in the Diskus device for the treatment of asthma. Am J Respir Crit Care Med 2000; 161: 527-534.

11. Bateman ED, Britton M, Carrillo J, Almeida J, Wixon C. Salmeterol/fluticasone combination inhaler. A new, effective and well-tolerated treatment for asthma. Clin Drug Invest 1998; 16: 193-201.

12. Chapman KR, Ringdal N, Backer V, Palmqvist M, Saarelainen S, Briggs M. Salmeterol and fluticasone propionate $(50 / 250 \mathrm{mcg})$ administered via combination Diskus inhaler: as effective as when given via separate Diskus inhalers. Can Respir J 1999; 6: 45-51.

13. Aubier M, Pieters W, Schlösser N, Steinmetz K-O. Salmeterol/fluticasone propionate $(50 / 500 \mu \mathrm{g})$ in combination in a Diskus $\mathbb{R}$ inhaler (Seretide $\mathbb{R}$ ) is effective and safe in the treatment of steroid-dependent asthma. Respir Med 1999; 93: 876-884.

14. van den Berg NJ, Ossip MS, Hederos CA, Anttila H, Ribeiro BL, Davies PI. Salmeterol/fluticasone propionate $(50 / 100 \mu \mathrm{g})$ in combination in a Diskus $\mathbb{R}$ inhaler (Seretide $\mathbb{B}$ ) is effective and safe in children with asthma. Pediatr Pulmonol 2000; 30: 97-105.

15. Johansson G, McIvor RA, Purello D'Ambrosio F, Gratziou DR, James MH. Seretide (salmeterol 50 $\mathrm{mcg} /$ fluticasone propionate $100 \mathrm{mcg}$ bid) compared with budesonide ( $400 \mathrm{mcg}$ bid) in mild to moderate asthma. Am J Respir Crit Care Med 1999; 159: A637.

16. Jenkins C, Woolcock AJ, Saarelainen P, Lundbäck B, James MH. Salmeterol/fluticasone propionate combination therapy $50 / 250 \mu \mathrm{g}$ twice daily is more effective than budesonide $800 \mu \mathrm{g}$ twice daily in treating moderate to severe asthma. Respir Med 2000; 94: 715723.

17. Smith MA, Leeder SR, Jalaludin B, Smith WT. The asthma health outcome indicators study. Aust $N Z$ J Public Health 1996; 20: 69-75.

18. Santanello N, Zhang J, Seidenberg B, Reiss TF, Barber BL. What are minimal important changes for asthma measures in a clinical trial? Eur Respir J 1999; 14: $23-27$.

19. Malmstrom K, Rodriguez-Gomez G, Guerra J, et al. Oral montelukast, inhaled beclomethasone, and placebo for chronic asthma. Ann Intern Med 1999; 130: 487-495.

20. Zetterström O, Buhl R, Mellem $\mathrm{H}$, et al. The new single inhaler product containing both budesonide/ formoterol improves asthma control in adults. Eur Respir J 2000; 16: Suppl. 31, 455.

21. Cockcroft DW, Swystun VA. Asthma control versus asthma severity. J Allergy Clin Immunol 1996; 98: 1016-1018. 